\title{
NUMERICAL SIMULATION OF AN AXIAL COMPRESSOR WITH NONAXISYMMETRIC CASING TREATMENT
}

\author{
N. Gourdain, M. Montagnac, and J. F. Boussuge
}

This study deals with unsteady numerical simulation of casing treatment in a stage of an axial compressor. The stall inception process is first investigated in the compressor with smooth wall. At low mass flow, the simulation shows the development of large reversed flow regions near the casing that leads to rotating stall. Then, a simulation is performed for a compressor stage with casing treatment. Despite a strong impact on the rotor casing flow, the operating range extension is low, meaning that other processes like rotor/stator interactions may play a role in the loss of stability.

\section{NOMENCLATURE}

$\begin{array}{ll}P_{0} & \text { ambient pressure }(101325 \mathrm{~Pa}) \\ P_{i} & \text { downstream total pressure } \\ P_{i_{0}} & \text { upstream total pressure } \\ P_{s \mathrm{BC}} & \text { static pressure for the boundary condition } \\ Q & \text { mass flow } \\ Q_{n} & \text { nominal mass flow } \\ Q_{\mathrm{sch}} & \text { mass flow from the numerical scheme } \\ r & \text { radius } \\ R_{p i} & \text { total pressure ratio }\left(P_{i} / P_{i_{0}}\right) \\ T & \text { rotation period of the rotor }\left(2 \pi / \Omega_{R}\right) \\ u_{\tau} & \text { skin friction velocity } \\ V_{x, \theta, r} & \text { components of relative velocity } \\ x & \text { axial position } \\ y & \text { distance from the wall } \\ y^{+} & \text {nondimensional distance from the wall }\left(\rho y u_{\tau} / \mu\right) \\ \Delta Q & \text { mass flow range }\left(Q_{\text {max }}-Q_{\text {stall }}\right) \\ \lambda & \text { throttle parameter } \\ \rho & \text { density }\end{array}$

This is an Open Access article distributed under the terms of the Creative Commons Attribution-Noncommercial License 3.0, which permits unrestricted use, distribution, and reproduction in any noncommercial medium, provided the original work is properly cited. 
$\begin{array}{ll}\theta & \text { azimuth } \\ \Phi & \text { flow coefficient }\left(Q / Q_{n}\right) \\ \Omega_{R} & \text { rotor rotation speed }\end{array}$

\section{INTRODUCTION}

Aerodynamic instabilities are among the key phenomena for the design of a compressor. These flow phenomena have been studied for 50 years but the basic mechanisms linked to these unstable flows are not yet fully understood. Two kinds of instabilities can be observed: rotating stall and surge. These instabilities are responsible for strong vibrations that can damage the blades or lead to a complete failure of the machine in the case of surge. Today, motorists design compressors with a large surge margin. An increase in the performances of the compression system (pressure ratio or operability range) is necessary to reduce the weight of the system. A step to improve the design of compressors is to provide reliable tools to predict the stability limit in order to reduce the surge margin. Analytical models can give valuable information about the pressure rise and mass flow rate evolution during rotating stall or surge [1]. The model of Spakovszky [2] provides precious data concerning the stability of particular modes in the compressor and allows testing strategies for the control of unstable flows. Unfortunately, these analytical models are not capable of predicting accurately the position of the surge line. Today, due to the development of the computational power and the numerical methods, Computational Fluid Dynamics becomes a suitable tool to predict very complex flows. Many studies have recently shown that the numerical simulation is an efficient tool to compute rotating stall $[3,4]$ or surge $[5,6]$. During the past few years, many studies were carried out and showed that different elements play a role in the rotating stall (or surge) inception such as the tip leakage flow [7] and also the rotor/stator interaction $[8,9]$.

Today, it is well established that the tip leakage flow is responsible for the loss of stability in most cases. In order to control the flow in the tip leakage region, passive methods are a promising way to explore. For example, passive methods can be axisymmetric [10] or nonaxisymmetric $[11,12]$ casing treatments. Hathaway [13] proposed a new method based on casing bleed and injection. This self-recirculating casing treatment leads to an important extension of the stable operating range without penalty for the efficiency, in the case of a modern transonic rotor [14]. As a general rule, casing treatments allow a higher range of operability, a higher pressure rise but often a decrease of the efficiency. Moreover, all compressors do not have the same behavior with casing slots and some of them exhibit no increase in the stability [15]. Most of the studies about casing treatments consider only one rotor passage and a finite number of slots for each passage. It could be interesting to assess the capacity of casing treatment to 
extend operating range in the case of a compressor stage. The aim of the present work is thus to provide numerical data and discussion for one configuration of casing slots tested with an axial stage of a subsonic compressor.

This study focuses on two aspects: prediction of the stability limit with a full three-dimensional (3D) flow solver and understanding of the flow mechanisms that are responsible for the loss of stability with and without casing treatment. Section 2 deals with the test case, the casing slot geometry, and the numerical method. Descriptions of the compressor facility and the casing treatment are provided here. The numerical code used for this study and the numerical parameters are then described (schemes, boundary conditions). In section 3 , an unsteady 3D simulation on a part of the whole geometry with smooth wall is presented. Results from this calculation are analyzed with a particular interest for the flow evolution from the nominal point toward the stall inception point. This part shows some mechanisms about the role of the tip leakage flow at conditions near stall. In section 4, the simulation of a casing treatment solution is performed in order to increase the stable operating range of the compressor. Impacts on the performances with this configuration are estimated and modification of the tip leakage flow structure is highlighted. A spectral representation explains some of the basic mechanisms linked to the casing treatment in the present case. Then, the last section concludes on the validity of this method with respect to the objectives and some ways to explore are proposed.

\section{COMPRESSOR MODEL}

\subsection{Experimental Facility}

The test case used for this study is the Cme2 compressor. This axial subsonic compressor designed by SNECMA* is located at the LEMFI ${ }^{\dagger}$ (Orsay, France). It is composed of a single stage with one rotor of 30 blades and one stator of 40 blades. The nominal rotation speed is $6330 \mathrm{rpm}$ which corresponds to a relative tip Mach number of 0.534 ; so, the flow is perfectly subsonic in the entire compressor. This kind of low-power compressor is well suited to study instabilities because the risk of mechanical failure is low. The compressor has been chosen since previous studies have shown that the tip leakage flow plays a major role in the development of a particular kind of rotating stall [16]. A schematic view of this axial compressor is shown in Fig. 1 and the experimental facility is presented in Fig. 2. Measurements with probes wire and Laser Doppler Velocimetry are available for stable operating points and during rotating stall.

* SNECMA - Société Nationale d'Étude et de Construction de Moteurs d'Aviation.

${ }^{\dagger}$ LEMFI - Laboratory of Energetics and Internal Fluid Mechanics. 


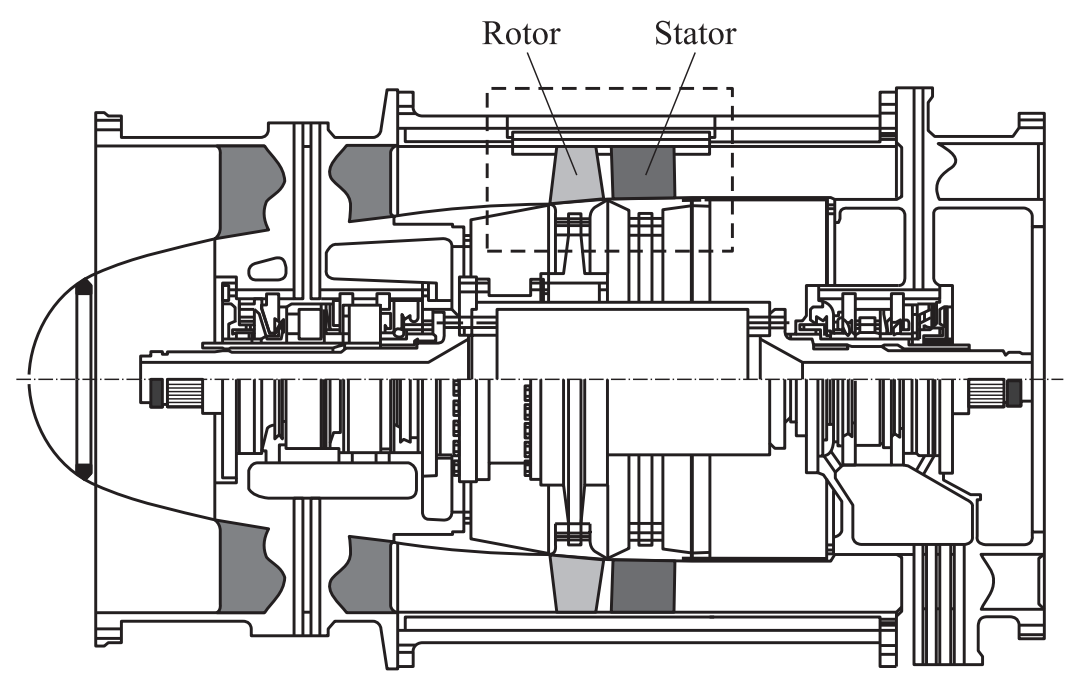

Figure 1 Cross section of the compressor test case

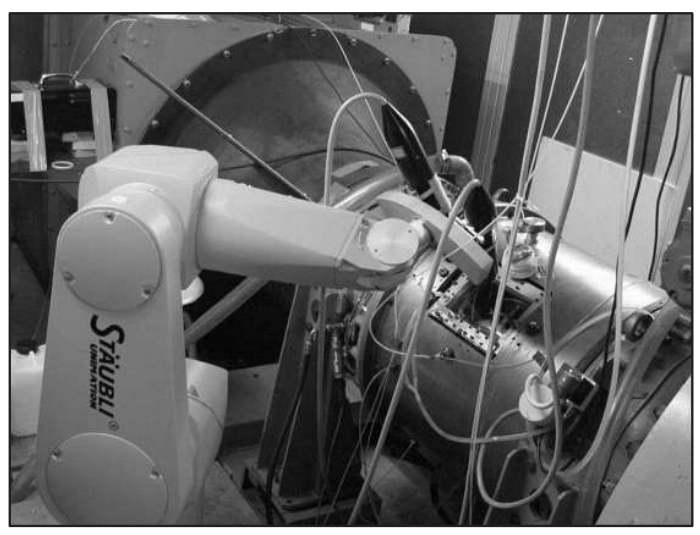

Figure 2 View of the experimental facility

Experimental studies were achieved in order to characterize the behavior of the compressor during stall inception and during rotating stall [17]. Table 1 gives some information about the aerodynamic performances and Table 2 gives the main geometric characteristics. The tip clearance of this compressor is about $1 \%$ of the rotor span. At the nominal operating point, the characteristics of the flow are $10.5 \mathrm{~kg} / \mathrm{s}$ for the mass flow and 1.152 for the pressure ratio. The nominal mass flow $Q_{n}$ is used to compute the flow coefficient $\Phi\left(=Q / Q_{n}\right)$. 
Table 1 Aerodynamic performances

\begin{tabular}{lc}
\hline Nominal pressure ratio & 1.152 \\
Nominal mass flow & $10.5 \mathrm{~kg} / \mathrm{s}$ \\
Measured efficiency & 0.92 \\
Nominal rotor speed & $6330 \mathrm{rpm}$ \\
Rotor speed at tip & $182 \mathrm{~m} / \mathrm{s}$ \\
Shaft power & $180 \mathrm{~kW}$ \\
\hline
\end{tabular}

Table 2 Geometrical characteristics

\begin{tabular}{lc}
\hline Tip radius & $0.275 \mathrm{~m}$ \\
Number of rotor blades & 30 \\
Number of stator blades & 40 \\
Rotor blade chord & $84 \mathrm{~mm}$ \\
Stator blade chord & $77 \mathrm{~mm}$ \\
Tip clearance & $0.5 \mathrm{~mm}$ \\
Hub to tip ratio & 0.78 \\
\hline
\end{tabular}

\subsection{Design of Casing Treatment}

The geometry of the casing treatment used for this study is largely based on the results from the studies of $[11,12]$. The present treatment is composed of 110 slots that are built equally spaced around the circumference of the rotor. Thus, the number of slots for each rotor passage is not an integer $(110 / 30 \approx 3.67)$. A view of the compressor with the casing treatment is shown in Fig. $3 a$ and the main geometric parameters of the slots are indicated in Fig. $3 b$. Each slot consists in a semicircular bend skewed cavity of $24 \mathrm{~mm}$ with a depth of $6 \mathrm{~mm}$ and a thickness of $4 \mathrm{~mm}$. The cavity is split in two segments: the first one is designed to align with the absolute flow angle at the entrance, and the second one is inclined of $45^{\circ}$ with respect to the axial direction. The second segment is also inclined of $25^{\circ}$ with respect to the radial direction in order to reduce the angle when the flow enters in the slot. Each slot extends from upstream the



(a)

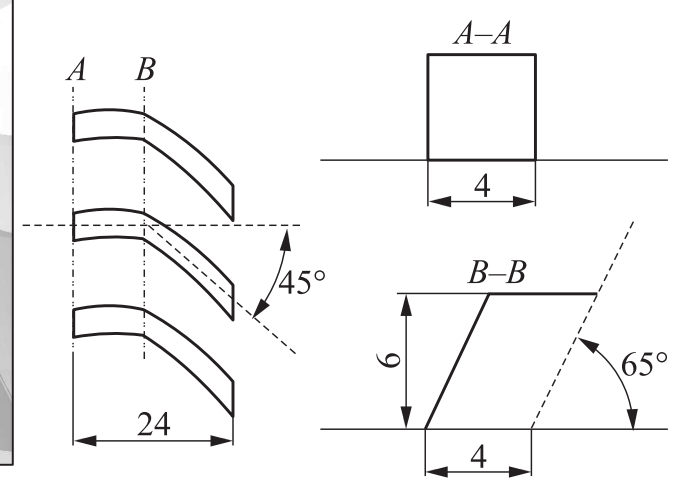

(b)

Figure 3 Configuration of casing treatment: $(a)$ compressor with casing treatment; and $(b)$ geometrical parameters of the slots $(x, \theta)$ and $(x, r)$ planes. Dimensions are in millimeters 
rotor to $25 \%$ of the rotor axial chord. The expected effect is to drive flow from the second segment of the slot that follows the rotor stagger angle to the leading edge of the rotor. The angle of the first segment leads to an injection upstream with the same angle than the inflow and thus minimizes the flow angle on the leading edge of the rotor.

\subsection{Meshing Strategy}

The 3D mesh of the compressor is designed with a multiblock strategy. A wall function approach is used to avoid mesh refinement problem near walls and to obtain a better convergence with larger time steps. The distance between the wall and the first mesh point is set to $40 \mu \mathrm{m}$. The node distribution for the different parts of the mesh is presented in Table 3. A view of the compressor mesh is shown in Fig. 4 and a radial plane of the mesh with the casing treatment is shown in Fig. 5. The mesh takes into account the tip leakage with 11 points in the radial direction. A standard nonmatching boundary condition is used between the tip mesh and the rotor passage mesh. For the simulation with a casing treatment, an unsteady boundary condition with nonmatching point has been developed. The nonrotating grids of the casing slots are linked to a very thin base $(10 \%$ of the tip clearance) that is connected to the rotor passages with a sliding interface. The advantage of this method is that the CPU requirement is not too important since the interpolation coefficients are computed only for two-dimensional (2D) windows. Moreover, this boundary condition is conservative in the case of a plane interface between blocks, which is roughly the case here. In order to avoid numerical instabilities from the boundary conditions, the model extends up to 0.6 radius of the compressor upstream and 0.5 radius downstream. Unsteady

Table 3 Computational grid dimensions

\begin{tabular}{lcc}
\hline & Rotor (one channel) & Stator (one channel) \\
\hline O-blade & $297 \times 19 \times 67$ & $171 \times 19 \times 57$ \\
H-upstream & $33 \times 57 \times 67$ & $9 \times 47 \times 57$ \\
H-channel & $59 \times 21 \times 67$ & $67 \times 25 \times 57$ \\
H-downstream & $15 \times 51 \times 67$ & $39 \times 41 \times 57$ \\
H-tip clearance & $131 \times 7 \times 11$ & - \\
Total & 648463 & 395922 \\
\hline \multicolumn{2}{c}{ Casing treatment } \\
\hline H-ring & $121 \times 353 \times 3$ \\
O-slot & $57 \times 17 \times 13(\times 11$ slots $)$ \\
H-slot & $33 \times 17 \times 13(\times 11$ slots $)$ \\
Total & 346929 \\
\hline
\end{tabular}




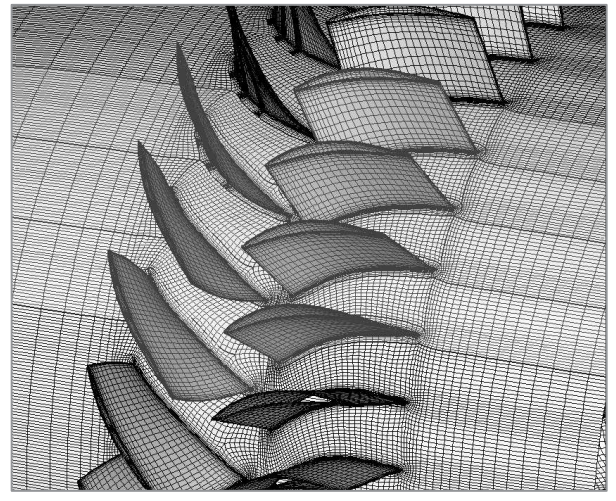

Figure 4 View of the 3D mesh with smooth wall (1 point over 2$)$

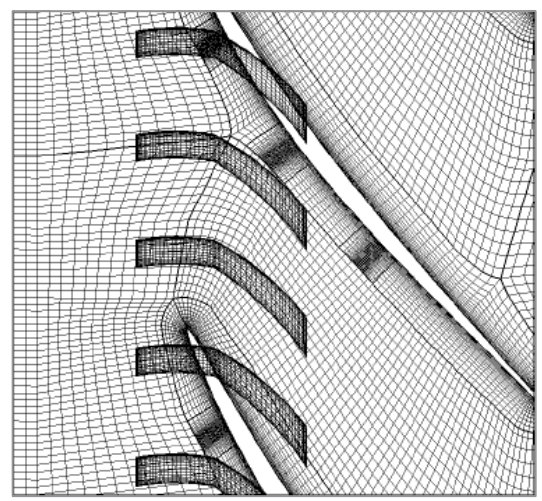

Figure 5 Blade-to-blade view of the mesh with casing treatment

simulations consider one tenth of the whole compressor geometry (3 rotor and 4 stator passages). Thus, the total number of mesh points for the smooth wall case is 3.57 millions of nodes and 3.92 millions with the eleven slots of the casing treatment.

\subsection{Numerical Method}

The governing equations are the Reynolds Averaged Navier-Stokes (RANS) equations describing the conservation of mass, momentum, and energy of the fluid. For the RANS system, the turbulent fluxes are modeled with classical eddy viscosity assumptions. The code used to solve this system of equations is the elsA software developed by ONERA and CERFACS [18]. The governing equations are integrated with a compressible finite volume formulation method and in the reference frame of each row. The time marching algorithm is a backward Euler scheme based on a Lower-Upper (LU) decomposition and the Symmetric Successive Overrelaxation (SSOR) resolution. For unsteady computations, a second-order Dual Time Stepping (DTS) method is used in order to define greater time steps than with a full explicit integration. For this study, all unsteady computations are done with 51 physical time steps for one rotor blade passage. This number of time steps is assumed to be sufficient to capture correctly physical structures near the tip with a reasonable number of subiterations [19]. The convective fluxes are discretized with a 2nd order centered Jameson scheme [20]. The 2nd and 4th order viscosity coefficients are applied to stabilize the numerical scheme. Boundary conditions, which are a key parameter for the simulation of instabilities in compressor, have been validated in 
a previous study [16]. A condition of spatial periodicity is applied for the lateral boundaries and a sliding interface condition is used between the rotor and the stator. A condition of purely axial injection at the inlet $\left(P_{0}=101325 \mathrm{~Pa}\right.$, $\left.T_{0}=288 \mathrm{~K}\right)$

$$
P_{s \mathrm{BC}}=P_{0}+\lambda Q_{\mathrm{sch}}^{2}
$$

and a throttle condition with a radial equilibrium at the outlet

$$
\frac{\partial P_{s \mathrm{BC}}}{d r}=\rho \frac{V_{\theta}^{2}}{r}
$$

are both applied. To describe the characteristic of a compressor, the throttle parameter $\lambda$ is set to different values, generally from the choked point toward the stall inception point. One advantage of this boundary condition is the possibility to simulate the peak of pressure ratio and operating points with lower mass flow.

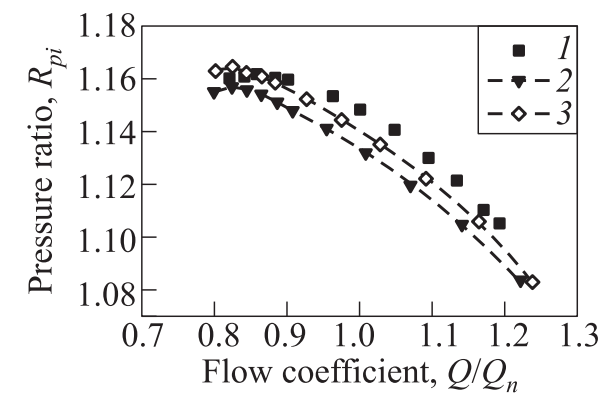

Figure 6 Influence of the turbulence model (averaged steady calculations): 1 - measurements; 2 - elsA - Spalart-Allmares [21]; and $3-e l s A-k-\omega[22]$

stator rows. The computed $y^{+}$, which is an important parameter for the wall function approach, is found to be around 20. A better description of the adiabatic wall law used here can be found in [23]. The slope of the characteristic is well predicted by both calculations. However, the position of the pressure peak is not well estimated by the simulations. One explanation is the use of the mixing plane that does not capture correctly potential effects. For this application, the $k-\omega$ turbulence model gives more precise results for the description of the compressor characteristic. The main reason is that the calculation with the Spalart-Allmaras model exhibits an overestimated stall in the stator blade row, which is responsible for strong losses and thus for worse performance prediction. Finally, the $k-\omega$ turbulence model of Wilcox is chosen for this study. 


\section{SIMULATION OF SMOOTH WALL CASE}

Unsteady calculations are achieved with a numerical method presented in the previous section. The rotation speed is set at the nominal speed $(6330 \mathrm{rpm})$. The aim is to describe the compressor characteristic with smooth wall at nominal rotation speed and to obtain the data on the flow near stall. The configuration simulated represents a tenth of the compressor circumference, i.e., 3 rotor passages and 4 stator passages. Ten subiterations for the DTS scheme are enough to loose 2 orders of magnitude for the normalized residuals. Computations are performed using a Cray xd1 server with 8 AMD Opteron processors. The total CPU time for one operating point (i.e., one value of the throttle parameter) is $140 \mathrm{~h}$ for a memory cost of 6.7 Go. Mass flow evolution at the compressor outlet is shown in Fig. 7 for a near-stall point. The corresponding flow coefficient is $\Phi=0.827$. For a signal registered at the stator exit, a periodic state is reached after 2 rotor revolutions, i.e., 60 rotor blade passages. Figure 8 shows a comparison between the computed characteristic and the experimental data. The pressure ratio is slightly underestimated, probably due to the numerical dissipation used with the Jameson scheme. However, the position of the total pressure ratio peak is well estimated.

The experimental stall inception point is found at $\Phi=0.816$. Experimentally, rotating stall is the first instability which develops at low mass flow rate. After a short transient, a large cell of rotating blocked flow appears in the rotor blade row, near the casing. This cell evolves towards a full span stall cell which extends on a third of the whole circumference and moves at a constant speed of $40 \%$ of the rotor rotation speed [17]. The numerical model is not able to reproduce this behavior. The main reason is that spatial wavelengths lower than $2 \pi / 10$ are filtered by the periodic boundary conditions; so, the simulation is

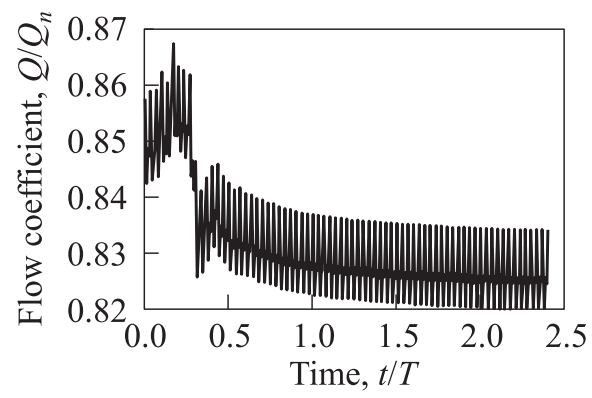

Figure 7 Mass flow evolution at outlet $(\Phi=0.827)$



Figure 8 Computed characteristic and experimental data (unsteady calculations): $1-$ measurements; and $2-3 \mathrm{D}$ els $A$ calculation 


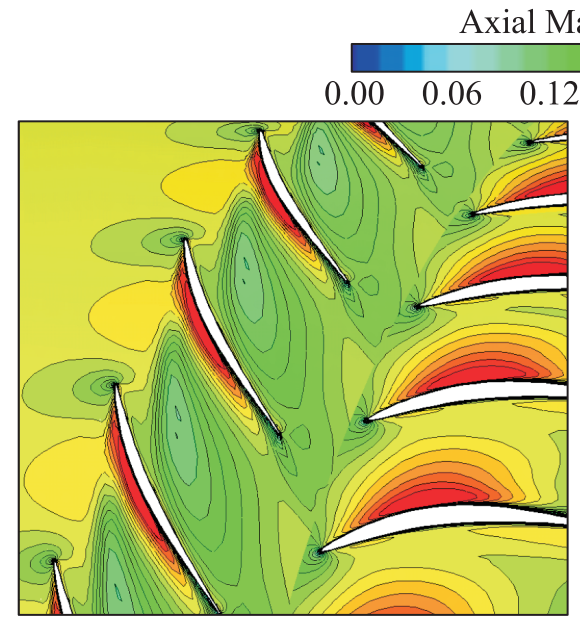

(a)



(b)

Figure 9 Time-averaged solution for the axial velocity flow field at $h / H=98 \%$ : (a) nominal point $(\Phi=1.02)$; and $(b)$ near-stall point $(\Phi=0.827)$. (Refer Gourdain et al., p. 602.)

not able to represent correctly the experimental rotating stall cell. Nevertheless, the simulation can compute the aerodynamic stability limit with a reasonably good accuracy [4]. The physical time needed to obtain instabilities can be very important (more than hundreds rotor revolutions). For CPU time reason, it is not possible to simulate such a time. Thus, in the present paper, the stability of a point is estimated after a time corresponding to more than 2 rotor revolutions, which corresponds to a balance between reasonable computational time and sufficient time to observe instabilities. The operating point is considered to be stable if there is no sign of instabilities at the end of the simulation (low frequencies or long spatial wavelength modes). With this assumption, the numerical stall inception point is found between $\Phi=0.813$ (last converged point) and $\Phi=0.80$ (first unstable one). The dashed region in Fig. 8 indicates the part of the characteristic for which the compressor operates with rotating stall conditions.

The head of the compressor is considered to be the critical zone for the development of instabilities. Thus, the analysis focuses on the flow evolution near the casing. Figures $9 a$ and $9 b$ show the time-averaged flow of axial velocity for a point near the nominal point $(\Phi=1.02)$ and for a near-stall point $(\Phi=0.827)$. Slices are built at $98 \%$ of the rotor span and the flow comes from the left towards the right. At the nominal point, there is no region of blocked flow for this span. At partial mass flow, Fig. $9 b$ shows that two phenomena develop in the rotor 
passages near the casing. A first large low-momentum zone near the leading edge of the rotor is visible. This flow structure is probably the result of the tip vortex transport by the mean flow. The flow blockage leads to an increase in the flow angle on the leading edge of the rotor and thus to a strong deviation of the flow in the rotor passage. A second zone of blocked flow exists for the last $50 \%$ of the rotor chord. A tip leakage vortex interacts with the boundary layer on the suction side of the rotor and induces a large deviation of the flow. The flow angle at the leading edge of the stator is then increased and leads to a separation of the boundary layer on the suction side of the stator blades.

This phenomenon is responsible for a strong deviation of the flow near the casing in the rotor/stator gap. A similar flow structure has been highlighted by Inoue et al. [9] for an axial subsonic compressor. When the mass flow dropped down under $\Phi=0.813$, large reversed zones grow and finally lead to a complete blockage of a large part of the rotor span. Then, structures that move at a fraction of the rotor speed develop in the compressor in about one revolution and lead to rotating stall.

\section{SIMULATION WITH CASING TREATMENT}

In order to increase the stability of the system, the compressor is now coupled with the casing treatment presented in subsection 2.2. Due to a higher memory cost $(+30 \%)$, the computations of the casing treatment case are performed using a NEC-SX8++ computer. Two hundred and seventy CPU hours are required to simulate one operating point. As for the smooth wall case, 72 rotor blade passages are simulated to estimate the stability of a point (i.e., more than 2 revolutions of the rotor). The results are presented in Fig. 10 which shows a
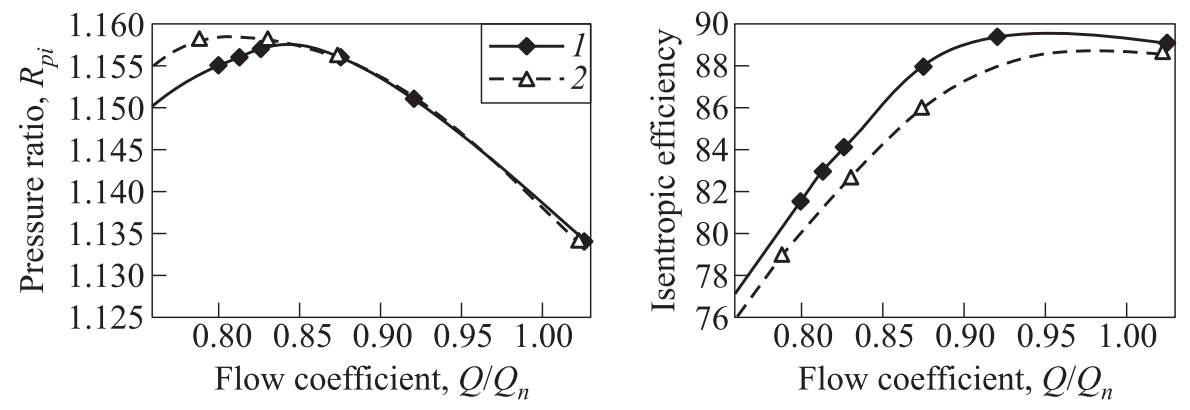

Figure 10 Comparison of the performances between smooth wall (1 - reference case) and casing treatment (2) 


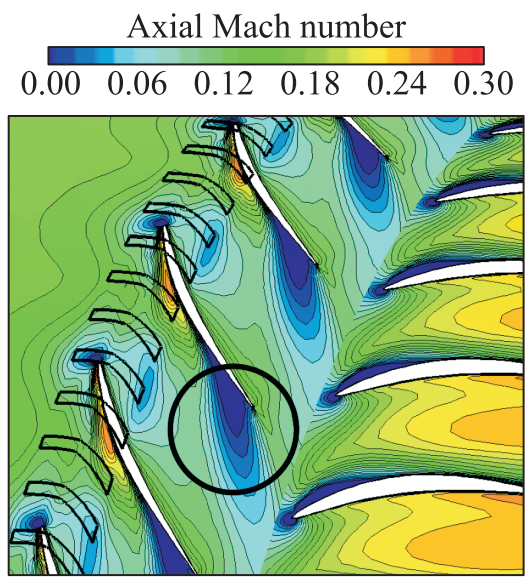

Figure 11 Time-averaged solution for the axial velocity flow field at $h / H$ $=98 \%(\Phi=0.830)$. (Refer Gourdain et al., p. 604.)

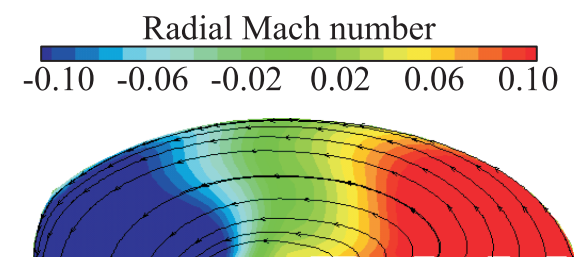

Figure 12 Time-averaged solution for the $(x, r)$ slice of radial velocity flow field in the middle of a slot $(\Phi=0.830)$. (Refer Gourdain et al., p.604.) comparison of the performances between the smooth wall case and the casing treatment case. The last stable point with casing slots is computed at $\Phi=0.789$ (instead of $\Phi$ $=0.813$ for the smooth wall). The operability range of the compressor is defined as $\Delta Q=Q_{\max }-Q_{\text {stall }}$. An increase of $6 \%$ in $\Delta Q$ is thus achieved with a slight decrease of the efficiency. Moreover, the pressure rise is increased at partial mass flow with nearly no penalty for the nominal operating point. Unfortunately, the extension of the stable range of the compressor is less important than found in literature $[12,24]$.

Figure 11 is a view of the timeaveraged axial velocity flow field at $98 \%$ of the rotor span. The corresponding mass flow of the operating point in Fig. 11 is $\Phi=0.830$. As expected, the casing treatment has completely removed the flow blockage near the leading edge of the rotor (when comparing with Fig. 9b). The main mechanism involved is the circulating flow inside the slot (Fig. 12) which drives fluid from the rear part of the slot to the leading edge of the rotor. This flow leads to an increase in the momentum near the casing and thus stabilizes the flow in the casing treatment region. However, the second zone of flow blockage on the last $50 \%$ of the rotor chord is not affected by the presence of slots (black circle in Fig. 11).

In order to better understand the physical mechanisms linked to the casing treatment, a Fourier transform is performed from an axial velocity signal near the casing. Figure $13 a$ shows a $2 \mathrm{D}$ representation of the existing spatial modes in the flow and Fig. $13 b$ is the representation of the spatial modes at the rotor/stator interface. Using the Tyler and Sofrin relation:

$$
m(n, b)=a N_{R} \pm b N_{S}
$$




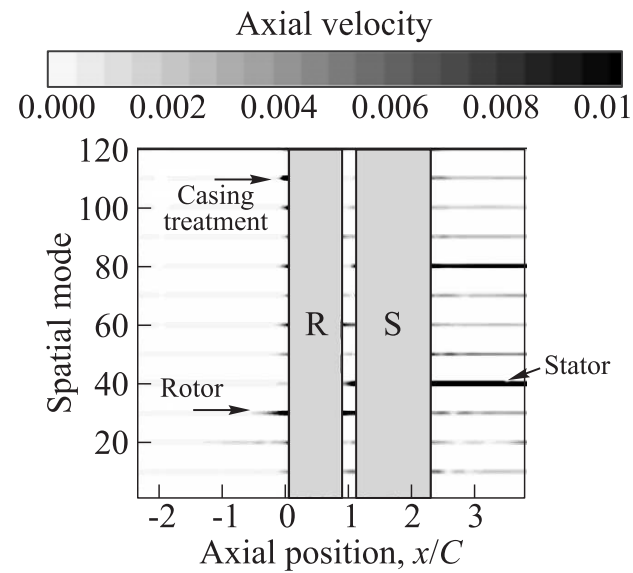

(a)

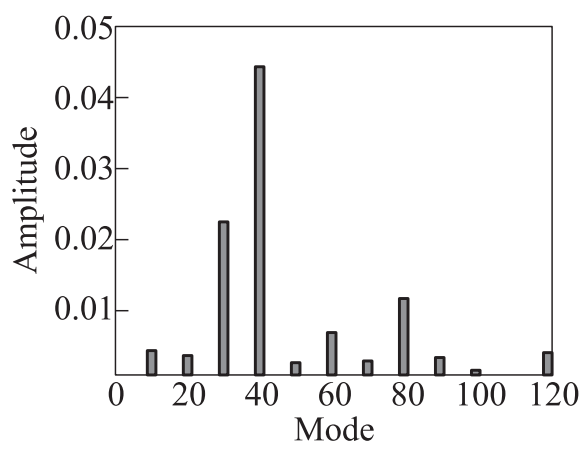

(b)

Figure 13 Spatial modes evolution $(\Phi=0.830)$ - axial velocity signal: $(a) 2 \mathrm{D}$ spatial modes representation at $h / H=98 \%$; and $(b)$ spatial modes at the rotor/stator interface

where $a$ and $b$ are the integers, it is possible to link a spatial mode $m$ with the corresponding flow structure. For example, the mode $m=30$ is linked to the rotor effects. Modes $m=10$ and 20 are the results of the rotor/stator interactions. Figure $13 a$ highlights the fact that the casing treatment (mode $m$ $=110$ ) has only a localized influence, just in front of the rotor. At the rotor/stator interface, no influence from the slots is visible. This fact explains why the second zone of flow blockage has not been removed by the casing treatment. Moreover, Fig. $13 b$ shows that at interface, the most important mode for the axial velocity comes from the potential effects of the stator (mode $m=40$ ). The strong influence of the stator on the rotor plays probably a role on the development of the second zone of blocked flow. A pulsation of this flow is also observed and is linked directly to the stator frequency (in the relative frame of the rotor). That means the stator influences the stability limit though the development of a massive boundary layer separation on the suction side of the rotor.

\section{CONCLUDING REMARKS}

This study has investigated the development of flow structures in a subsonic compressor at conditions near stall. Results show that two zones of reversed flow develop in the rotor when the mass flow is reduced, near the casing. One of these zones is located near the leading edge of the rotor, and the other one is 
located near the suction side on the last $50 \%$ of the rotor chord. The resulting flow blockage leads to the development of large boundary layer separation and to particular flow structures that move at a fraction of the rotor speed. These structures grow when the mass flow is reduced and finally lead to rotating stall.

A 3D numerical study has been performed to assess the capacity of casing treatment to extend the operating range of the compressor. The tested configuration has successfully removed a part of the flow blockage near the leading edge of the rotor. Unfortunately, the localized action of the casing slots has no effect on the development of the flow blockage near the trailing edge of the rotor blades. The extension of the stable range of the compressor is thus only slightly increased $(+6 \%)$ even if the maximum of pressure rise has also been positively impacted. It is assumed that the development of boundary layer separation is also strongly influenced by the stator potential effects, especially near the trailing edge of the rotor.

Further investigations are needed in order to precise the role of the rotor/stator interactions on the stability of this system. A simulation of the isolated rotor can be the first step to explore the role of the stator on the development of the casing flow blockage. The second step will be the design of a new kind of casing treatment to better stabilize the flow.

\section{ACKNOWLEDGMENTS}

The authors acknowledge SNECMA to give authorization to use the Cme2 geometry for this study. The authors would like to thank Dr. H. Miton from the LEMFI for providing experimental data that were used to validate the numerical simulations. Authors would also acknowledge S. Burguburu and ONERA to provide efficient tools for computing performances of the compressor.

\section{REFERENCES}

1. Moore, F.K., and E.M. Greitzer. 1985. A theory of post-stall transients in axial compression systems. Part I: Development of equations. Part II: Applications. ASME Paper Nos. 85-GT-171 and No. 85-GT-172.

2. Spakovszky, Z. 2001. Application of axial and radial compressor dynamic system modeling. Ph.D. Thesis. Massachusetts Institute of Technology, USA.

3. Schmidtmann, O., and J. M. Anders. 2001. Route to surge for a throttled compressor - a numerical study. J. Fluids Structures 15:1105-21.

4. Gourdain, N., S. Burguburu, G. J. Michon, N. Ouayahya, F. Leboeuf, and S. Plot. 2006. About the numerical simulation of rotating stall mechanisms in axial compressors. ASME Turbo Expo 2006. Barcelona, Spain. Paper No. 2006-90223. 
5. Niazi, S. 2000. Numerical simulation of rotating stall and surge alleviation in axial compressor. Ph.D. Thesis. Georgia Institute of Technology, USA.

6. Tauveron, N., P. Ferrand, F. Leboeuf, N. Gourdain, and S. Burguburu. 2006. Numerical contribution to the analysis of surge inception and development in axial compressors. In: Turbomachines: Aeroelastisity, aeroacoustics, and unsteady aerodynamics. Eds. V. Skibin, V. Saren, and S. Frolov. Moscow: TORUS PRESS. 340-55.

7. Bergner, J., D. K. Hennecke, and C. Hah. 2005. Tip clearance variations of an axial high-speed single stage transonic compressor. 17th Symposium on Airbreathing Engines. Munich, Germany. Paper No. ISABE-2005-1096.

8. He, L. 1997. Computational study of rotating-stall inception in axial compressors. J. Propulsion Power 13(1):31-38.

9. Inoue, M., M. Kuroumaru, S. Yoshida, T. Minami, K. Yamada, and M. Furukawa. 2004. Effect of tip clearance on stall evolution process in a low-speed axial compressor stage. ASME Turbo Expo. Vienna, Austria. Paper No. GT2004-53354.

10. Shabbir, A., and J. J. Adamczyk. 2004. Flow mechanism for stall margin improvement due to circumferential casing grooves on axial compressors. American Society of Mechanical Engineers. Paper No. GT2004-53903.

11. Wilke, I., and H.P. Kau. 2004. A numerical investigation of the flow mechanisms in a high pressure compressor front stage with axial slots. J. Turbomachinery 126(3):339-49.

12. Lu, X., W. Chu, J. Zhu, and Y. Wu. 2006. Experimental and numerical investigation of a subsonic compressor with bend skewed slot casing treatment. ASME Turbo Expo 2006. Barcelona, Spain. Paper No. 2006-90026.

13. Hathaway, M. 2002. Self recirculating casing treatment concept for enhanced compressor. ASME Turbo Expo. Amsterdam, The Netherlands. Paper No. 2002-30368.

14. Iyengar, V., L. Sankar, and S. Niazi. 2005. Assessment of the self recirculating casing treatment concept to axial compressors. AIAA Paper No. 2005-0632.

15. Brignole, G., H.P. Kau, and I. Wilke. 2005. Numerical evaluation of important parameters ruling the effectiveness of casing treatments in transonic compressor. 17th Symposium on Airbreathing Engines. Munich, Germany. Paper No. ISABE2005-1095.

16. Gourdain, N. 2005. Simulation Numérique des Phénomènes de Décollement Tournant dans les Compresseurs Axiaux. Ph.D. Thesis. Ecole Centrale of Lyon, France.

17. Michon, G. J., H. Miton, and N. Ouayahya. 2005. Experimental study of the unsteady flows and turbulence structure in an axial compressor from design to rotating stall conditions. 6th Conference (European) on Turbomachinery. Lille, France. Paper No. 015-03/39.

18. Cambier, L., and M. Gazaix. 2002. An efficient object oriented solution to CFD complexity. AIAA Paper No. 2002-0108.

19. Lu, X., W. Chu, J. Zhu, and Y. Wu. 2006. Mechanisms of the interaction between casing treatment and the tip leakage flow in a subsonic axial compressor. ASME Turbo Expo. Barcelona, Spain. Paper No. 2006-90077. 
20. Jameson, A., W. Schmidt, and E. Turkel. 1981. Numerical solution of the Euler equations by finite volume methods using Runge-Kutta time stepping schemes. AIAA Paper No. 81-1259.

21. Spalart, P. R., and S.R. Allmaras. 1992. A one equation turbulence model for aerodynamic flows. 30th Aerospace Science Meeting and Exhibit. Reno.

22. Wilcox, D.C. 1988. Reassesment of the scale determing equation for advanced turbulence models. AIAA J. 26(11):1299-310.

23. Goncalvès, E. 2001. Implantation et Validation de Loi de Paroi dans un code Navier-Stokes. Thése de Doctorat. Ecole Nationale Supérieure de l'Aéronautique et de l'Espace.

24. Yang, H. 2003. Unsteady flow simulation of a transonic compressor coupled with casing treatment. 11th Annual Conference of CFD Society of Canada. Vancouver, Canada. 